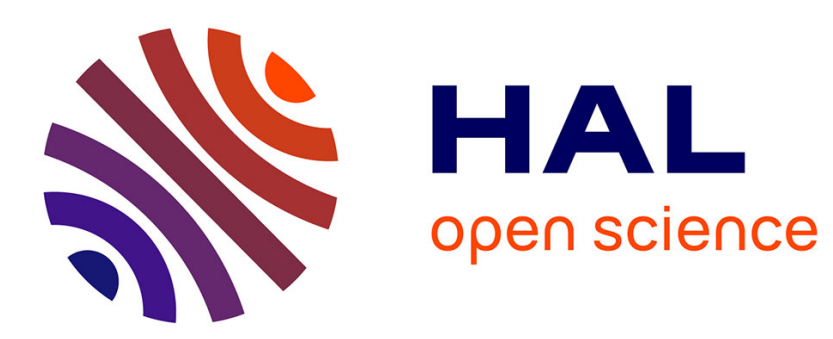

\title{
Characterization and charge transfer properties of organic BODIPY dyes integrated in TiO 2 nanotube based dye-sensitized solar cells
}

I. Gonzalez-Valls, A. Mirloup, T. Le Bahers, N. Keller, Thomas Cottineau, P. Sautet, V. Keller

\section{To cite this version:}

I. Gonzalez-Valls, A. Mirloup, T. Le Bahers, N. Keller, Thomas Cottineau, et al.. Characterization and charge transfer properties of organic BODIPY dyes integrated in TiO 2 nanotube based dye-sensitized solar cells. RSC Advances, 2016, 6 (94), pp.91529-91540. 10.1039/C6RA14152H . hal-02384160

\section{HAL Id: hal-02384160 https://hal.science/hal-02384160}

Submitted on 28 Nov 2019

HAL is a multi-disciplinary open access archive for the deposit and dissemination of scientific research documents, whether they are published or not. The documents may come from teaching and research institutions in France or abroad, or from public or private research centers.
L'archive ouverte pluridisciplinaire HAL, est destinée au dépôt et à la diffusion de documents scientifiques de niveau recherche, publiés ou non, émanant des établissements d'enseignement et de recherche français ou étrangers, des laboratoires publics ou privés. 


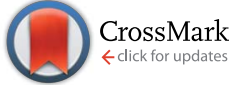

Cite this: RSC Adv., 2016, 6, 91529

Received 31st May 2016

Accepted 19th September 2016

DOI: 10.1039/c6ra14152h

www.rsc.org/advances

\section{Characterization and charge transfer properties of organic BODIPY dyes integrated in $\mathrm{TiO}_{2}$ nanotube based dye-sensitized solar cells $\uparrow$}

\author{
I. Gonzalez-Valls, ${ }^{\star a}$ A. Mirloup, ${ }^{a}$ T. Le Bahers, ${ }^{b}$ N. Keller, ${ }^{a}$ T. Cottineau, ${ }^{\text {*a }}$ P. Sautet ${ }^{\mathrm{b}}$ \\ and V. Keller ${ }^{\mathrm{a}}$
}

In this work, dye-sensitized solar cells using vertically-aligned $\mathrm{TiO}_{2}$ nanotubes grafted with an organic BODIPY dye are presented for the first time. The properties and performance of the BODIPY cells are compared to the ones of cells with a similar architecture but sensitized with the commercial N719 dye. The individual BODIPY dye molecules have 27 time higher photon-to-electron conversion efficiency than N719 dye molecules. Then, even with 100 times less BODIPY molecules grafted on the surface of the $\mathrm{TiO}_{2}$ nanotubes, the power conversion efficiency of the cells with BODIPY dye only decreased by a factor of 4 when compared to cells with N719 dye. This suggests good light absorption and charge transfer of the BODIPY molecules. Spectroscopic and electrochemical impedance methods were combined to experimentally measure the photochemical properties of the BODIPY dye and to explain the performance differences between solar cells based on the two dyes. Moreover, density function theory calculations were carried out to determine the electronic structure of the BODIPY molecules and allow to propose modifications of their chemical structures that would further enhance their solar to electrical energy conversion efficiency.

\section{Introduction}

Dye-sensitized Solar Cells (DSCs) are promising solar energy conversion devices owing to good efficiency for a low production cost and the possibility to produce flexible and transparent devices. ${ }^{1}$ These solar cells consists of a porous layer of large band gap semiconductor nanoparticles (NPs), as an electron transport material, with a light absorbing dye grafted on its surface. The cell is completed with an electrolyte that ensures the regeneration of the dye molecules by electron coming back from the counter electrode. Up to now, the highest Power Conversion Efficiency (PCE) for DSCs based on titanium dioxide $\left(\mathrm{TiO}_{2}\right)$ NPs has reached $14 \% .^{2}$ To further improve this efficiency several groups around the world are trying to improve the different components of the DSCs (light absorber, charge transport material, electrolyte etc.). In this work, we investigated a new cell architecture based on a BODIPY dye grafted on aligned $\mathrm{TiO}_{2}$ nanotubes (NTs).

${ }^{a}$ ICPEES, Institut de Chimie et Procédés pour l'Énergie, l'Environnement et la Santé, CNRS/Université de Strasbourg, 25 rue Becquerel, 67087 Strasbourg, France. E-mail: cottineau@unistra.fr

${ }^{b}$ Laboratoire de Chimie, Ecole Normale Supérieure de Lyon, 46 Allée d'Italie, 69346 Lyon, France

$\dagger$ Electronic supplementary information (ESI) available: Optimization of the $\mathrm{TiO}_{2}$ NTs synthesis conditions, XRD analysis, initial tests of DSCs with the 3 BODIPY dyes, EIS parameters and bode plots of the EIS measurements and IPCE graphs. See DOI: $10.1039 / \mathrm{c} 6 \mathrm{ra} 14152 \mathrm{~h}$
Titanium dioxide is an intensively used semiconductor for its advantageous properties that make it a suitable material for many applications such as solar cells, ${ }^{3,4}$ water splitting devices $^{5-7}$ and self-cleaning surfaces ${ }^{8,9}$ among others. In the case of $1 \mathrm{D}$ vertically-aligned $\mathrm{TiO}_{2}$ nanostructures (i.e. nanotubes or nanorods), the high surface-to-volume ratio, the onedimensional charge transport and decreased photo-generated charge carrier recombination rate at grain boundaries should result in an improved electron transfer, ${ }^{\mathbf{1 0 1 1}}$ which is a limiting factor of the DSCs. ${ }^{12}$ The use of $\mathrm{TiO}_{2}$ NTs in DSC has attracted great interest over the last few years. The first report of $\mathrm{TiO}_{2} \mathrm{NTs}$ based DSCs was in $2003^{13}$ and to date such a structure achieved 9\% PCE. ${ }^{14}$

Regarding the light absorbing dye, the most used are commercial Ru(II) complex dyes, N719 or N3. However, ruthenium is a rare and expensive metal and hence, there is a strong interest in finding a suitable metal-free sensitizer with low-cost, good absorption properties and suitable energy levels for a good charge transfer toward the semiconducting material. Organic dyes usually have high molar absorption coefficients compared to $\mathrm{Ru}(\mathrm{II})$ complex dyes and they can be prepared and purified in a wide range of solvents. The molecular design of the organic dyes, by substitution on the chromophore chemical structure, allows a control of their photo-physical, electrochemical and stereo-chemical properties..$^{15,16}$ Many different novel metal-free dyes have been synthesized and tested in DSCs such as porphyrin, ${ }^{17}$ perylene,${ }^{18}$ indoline, ${ }^{19}$ coumarin ${ }^{20}$ and 
polythyophene $\mathrm{e}^{\mathbf{2 1 , 2 2}}$ sensitizers. One of these sensitizers, boron dipyrromethene (BODIPY) fluorophore is easy to synthesize, stable and present good solubility. This family of BODIPY dyes also has strong absorption coefficients, large quantum yields and long excited-state lifetime. ${ }^{23-26}$ Despite all these properties, BODIPY dyes have been rarely integrated in DSCs (and only with $\mathrm{TiO}_{2}$ NPs), ${ }^{23,27-33}$ but they were mainly used in light emitting devices, ${ }^{34-36}$ chemical sensors ${ }^{34,35,37}$ or for biochemical labeling..$^{34,38}$

In this work, we present for the first time the combination of a BODIPY dye with vertically-aligned $\mathrm{TiO}_{2}$ NTs applied to DSCs. To date there are only very few studies on the use of organic dyes with $\mathrm{TiO}_{2}$ NTs for DSCs. ${ }^{39-41}$ Furthermore, all these references were measured in back-illumination, with $\mathrm{TiO}_{2}$ NTs synthesized on titanium foils and illuminated through the platinum counter-electrode. With this design, a part of the incident light does not reach the nanostructurated electrode due to reflection on the counter electrode and absorption by the electrolyte. In this study, we aim to graft the BODIPY dye on $\mathrm{TiO}_{2}$ NTs grown on a transparent conductive glass electrode allowing measurements in front illumination configuration.

First, three different BODIPY molecules, presented in Fig. 1, were synthesized and grafted on $\mathrm{TiO}_{2}$ NTs grown on titanium foil and tested in a back illumination configuration. Then, the BODIPY DSCs presenting the most promising efficiency (B3), was further studied and grafted on the $\mathrm{TiO}_{2}$ NTs grown on conductive glass electrode and tested in front illumination configuration. The performance of these cells were then compared to the ones of similar DSCs sensitized with the N719 dye. The quantity of grafted dye was evaluated by UV visible spectroscopy and used to determine the photon to electron conversion efficiency for a single molecule. Even with 100 times more N719 than BODIPY molecules grafted on $\mathrm{TiO}_{2}$ NTs surface, the PCE of the corresponding cell only increases by a factor of 4 . This suggests a good light absorption and an efficient charge transfer of the BODIPY molecules. Electrochemical Impedance Spectroscopy (EIS) experiment was used to understand the different behaviour of BODIPY and N719 based DSCs in terms of electron recombination and transfer processes. This study is completed by Density Function Theory (DFT) calculations in order to determine the structure of the
BODIPY molecules and to characterize the photo-induced charge transfer under irradiation. This information is important to identify different limiting points and to propose modifications that can be brought to the BODIPY in order to increase the electron injection from the dye to the $\mathrm{TiO}_{2}$.

\section{Experimental section}

All chemicals were used as received, without further purification: ethanol (EtOH absolute anhydrous pure, Carlo Erba), ethylene glycol (99.5\% Sigma-Aldrich), acetonitrile (ACN, 99.8\%, Sigma-Aldrich), tert-butanol $\left({ }^{t} \mathrm{BuOH}, 99.5 \%\right.$, SigmaAldrich), ammonium fluoride $\left(\mathrm{NH}_{4} \mathrm{~F}, 98 \%\right.$, Sigma-Aldrich), potassium hydroxide (KOH, Fluka).

\section{Preparation of $\mathrm{TiO}_{2}$ NT electrodes}

The $\mathrm{TiO}_{2}$ NTs were synthesized on Fluorine-doped Tin Oxide (FTO) slides (6-8 $\Omega ; 2.2 \mathrm{~mm}$ thick glass, Solems) by a two-step process. First, a layer of metallic titanium (Neyco, Ti 99.99\%) was deposited by Physical Vapor Deposition (PVD) on FTO using a DC magnetron sputtering evaporator (Alliance concept DP650). Before Ti deposition, the FTO slides were cleaned with soap, $\mathrm{H}_{2} \mathrm{O}$, EtOH and dried under $\mathrm{N}_{2}$ stream. Then, the samples were placed under vacuum $\left(1 \times 10^{-8}\right.$ Torr $)$ and their surface was exposed for $30 \mathrm{~s}$ to Ar plasma etching. The substrates were heated to $50{ }^{\circ} \mathrm{C}$ and the deposition duration was adjusted to reach a titanium film thickness of $\sim 2 \mu \mathrm{m}$ (electrode $\mathrm{A}$ ) and $\sim 4$ $\mu \mathrm{m}$ (electrode B).

The second step of the synthesis was the electrochemical anodization of the metallic Ti layer to obtain the $\mathrm{TiO}_{2} \mathrm{NTs}^{\mathbf{4 2 , 4 3}}$ The anodization was conducted in a two electrodes cell (Pt foil as counter electrode) using a Biologic SP-300 potentiostat with a $48 \mathrm{~V}$ booster module. The electrolyte temperature was kept constant by a thermocryostat. The anodization conditions were first optimized to obtain opened and well defined nanotubes (details in ESI $\dagger$ ). The most homogeneous synthesis was obtained with an electrolyte composed of $0.5 \%{ }_{\mathrm{w} / \mathrm{w}} \mathrm{NH}_{4} \mathrm{~F}$ and $3 \% \mathrm{v} / \mathrm{v}$ $\mathrm{H}_{2} \mathrm{O}$ in ethylene glycol at $25^{\circ} \mathrm{C}$ with an applied potential of $45 \mathrm{~V}$. This potential was applied until the Ti layer was fully oxidized and the electrode became transparent. Finally, to crystallise the

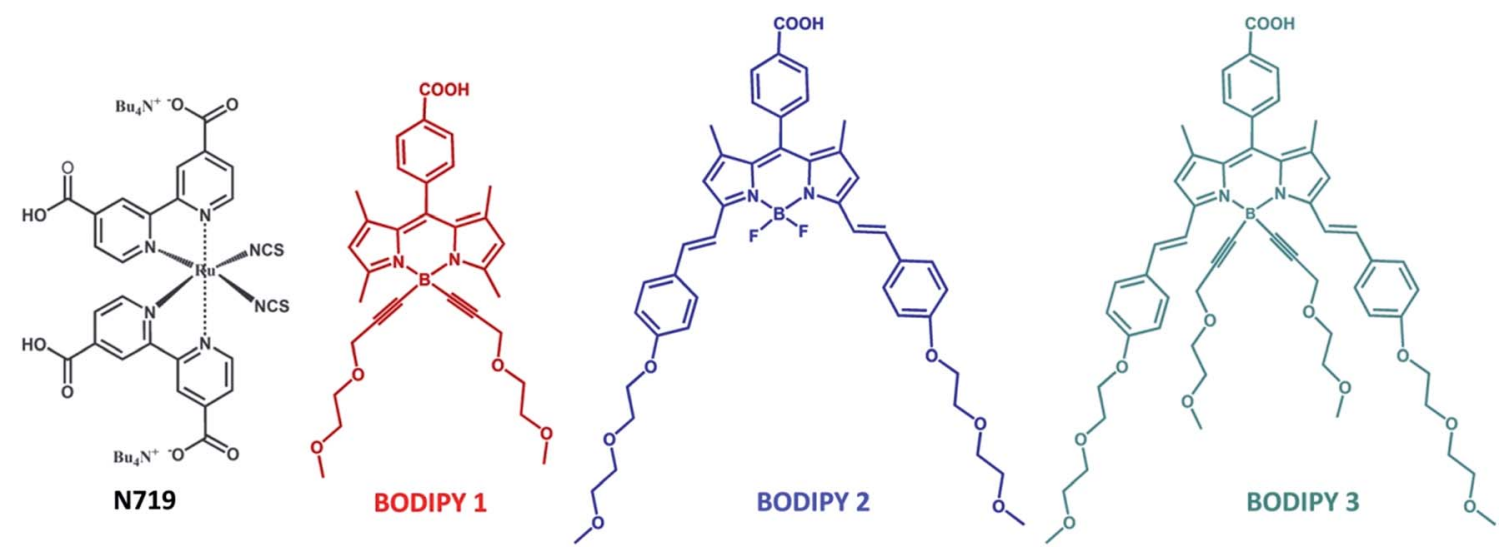

Fig. 1 Molecular structures of the commercial dye N719 and the synthesized BODIPY dyes: B1, B2 and B3. 
$\mathrm{TiO}_{2} \mathrm{NTs}$, the electrodes were annealed at $450{ }^{\circ} \mathrm{C}$ for $6 \mathrm{~h}$. For the initial DSCs tests, $\mathrm{TiO}_{2}$ NTs were prepared according to the same procedure, but on titanium foil (MaTeck GmbH, Ti 99.9\%) with an electrolyte containing $0.3 \%_{\mathrm{w} / \mathrm{w}} \mathrm{NH}_{4} \mathrm{~F}$ and $1 \% \%_{\mathrm{v} / \mathrm{v}} \mathrm{H}_{2} \mathrm{O}$.

\section{Dye-sensitized solar cells preparation}

The synthesis of the BODIPY dyes was carried out as reported in previous work. ${ }^{23-25,44}$ Fig. 1 shows the chemical structures of the three BODIPY dyes studied and the N719 dye (Ru 535-bisTBA, Solaronix). The $\mathrm{TiO}_{2}$ NTs electrodes A and B were immersed in a solution of commercial N719 or BODIPY dye at $0.5 \mathrm{mM}$ concentration. Different solvents $(\mathrm{EtOH}, \mathrm{ACN}$ and $\mathrm{ACN} / \mathrm{tBuOH}$ $(1: 1))$, temperature $\left(20\right.$ and $\left.50{ }^{\circ} \mathrm{C}\right)$ and immersion duration ( $8 \mathrm{~h}, 16 \mathrm{~h}$ and $24 \mathrm{~h}$ ) were tested for dye grafting. The optimal dye adsorption was observed for $16 \mathrm{~h}$ at $50{ }^{\circ} \mathrm{C}$ using EtOH for the N719 dye and the mixture ACN/ $t \mathrm{BuOH}$ for the BODIPY dyes. The counter electrode was platinized FTO slide $(70-100 \Omega ; 1.1 \mathrm{~mm}$ thick glass; Solems), prepared by tape casting (Pt-Catalyst T/SP, Solaronix) followed by a thermal treatment at $450{ }^{\circ} \mathrm{C}$ for 30 minutes. The electrodes were bounded thermally using a hot melt sealing foil (SX1170-60, Solaronix). Finally, the space between the two electrodes was filled with liquid electrolyte (Iodolyte AN-50, Solaronix).

\section{Density function theory calculations}

All DFT calculations were carried out with the Gaussian09 code. ${ }^{45}$ Structural optimizations and subsequent frequency calculations for the ground state were performed using an all electron Pople double zeta basis set with one polarization function on all atoms $(6-31 G(d))^{46,47}$ along with the hybrid functional PBE0. ${ }^{48}$ Vertical excitations were computed by the means of TD-DFT using a larger basis set, i.e. the $6-311+\mathrm{G}(2 \mathrm{~d}, \mathrm{p})$ basis set with the hybrid function M06-2X. ${ }^{49}$ The electronic transitions in BODIPY dyes are particularly difficult to model and have been the subject of several theoretical works both in TD-DFT and post-Hartree-Fock. While the large error generally made in TD-DFT in the simulation of the electronic transition is not well understood, it is sometimes ascribed to a not negligible contribution of double excitations. Post-Hartree-Fock methods, such as SAC-CI, are the best way to simulate such molecules. ${ }^{50}$ Unfortunately these methods are not tractable for large BODIPY dyes as the ones investigated here. But it has been proven that the M06-2X exchange-correlation functional leads to the smallest error in TD-DFT for simulating absorption spectrum of these dyes. ${ }^{49,51}$ Bulk solvent effects were included using the Polarizable Continuum Model (PCM). ${ }^{52}$ More specifically, the conductor-like PCM model as implemented in Gaussian (CPCM $)^{53}$ was applied and tetrahydrofuran was considered as solvent in analogy to the experimental measurement of absorption spectra. Default radii were used for structural optimizations. The density-based analysis and indices were obtained as described in previous work using a home developed code. $^{54,55}$

\section{Characterization methods}

The morphology and dimensions of $\mathrm{TiO}_{2}$ NTs were characterized by Scanning Electron Microscopy (FEG-SEM, JEOL 6700F).
The diameter and length of the $\mathrm{TiO}_{2}$ NT were evaluated with the Image ${ }^{\circledR}$ software by measuring the values for 10 NTs of each electrode. X-Ray Diffraction patterns (XRD) were measured using a Bruker D8 diffractometer equipped with a LynxEye detector $\left(\mathrm{Cu} \mathrm{K} \mathrm{K}_{\alpha} \lambda=0.1541 \mathrm{~nm}\right)$. The BODIPY dyes were characterized by UV-vis absorption spectroscopy using a Shimadzu UV-3600. Fluorescence spectra were recorded on a HORIBA fluoromax $4 \mathrm{P}$ spectrofluorimeter. Cyclic voltammetry measurements were performed in a conventional three electrodes system using a BAS CV-50W voltammetry analyzer equipped with a platinum microdisk $\left(2 \mathrm{~mm}^{2}\right)$ working electrode and a silver wire as counter-electrode. Ferrocene was used as internal standard and was calibrated against a Saturated Calomel Electrode (SCE). The electrolyte was $\mathrm{CH}_{2} \mathrm{Cl}_{2}$ containing $0.1 \mathrm{M} \mathrm{TBAPF}_{6}$ as supporting electrolyte. The quantity of grafted dye was measured by desorption: the electrodes were immersed in a $0.01 \mathrm{M} \mathrm{KOH}$ aqueous solution. Then, the solution containing the desorbed dye was analyzed by UV-visible spectrometry and the concentration calculated from the BeerLambert law. ${ }^{56}$ The DSCs efficiency was measured by $I-V$ curves and Electrochemical Impedance Spectroscopy (EIS) recorded under illumination and in the dark. The light source was a Xe arc lamp (Newport ${ }^{\circledR} 6259,300 \mathrm{~W}$ ) calibrated to obtain a power density of $50 \mathrm{~mW} \mathrm{~cm}{ }^{-2}$ reaching the cell surface. The incident photon to current conversion efficiency (IPCE) was measured with a monochromated Xe arc light source (using a Newport ${ }^{\circledR}$ Oriel 1/8m Cornerstone). The entrance and exit slits of the monochromator were set to obtain a resolution of $5 \mathrm{~nm}$. The power density arriving on the cell was monitored by a photodiode placed behind a beam sampler. A homemade LabView ${ }^{\circledR}$ program was used to control the measurements.

\section{Results and discussion}

\section{$\mathrm{TiO}_{2}$ nanotubes (NT) characterizations}

Fig. 2 shows SEM images of the sputtered Ti layer on electrodes A and $\mathrm{B}$ and the $\mathrm{TiO}_{2}$ NTs obtained with the optimized anodization conditions. This optimization was necessary to obtain well defined and open-ended nanotubes, indeed some residues of the deposited $\mathrm{Ti}$ layer can remain at the top of the nanotube layer. This layer was dissolved by increasing the activity of the $\mathrm{F}^{-}$by a higher $\mathrm{NH}_{4} \mathrm{~F}$ concentration and electrolyte temperature (details in ESI Table S1 and Fig. S2 $\dagger$ ). ${ }^{43}$ It was also necessary to optimize the duration of the anodization depending on the $\mathrm{Ti}$ layer thickness and electrolyte composition. This was done by following the current density during anodization (ESI Fig. S1†): the rise observed after the current plateau indicates the almost complete consumption of the Ti and then the electrode became transparent. The average NTs lengths were $2.4 \pm 0.4 \mu \mathrm{m}$ for electrode A and $4.4 \pm 1.1 \mu \mathrm{m}$ for electrode B. The nanotubes external and internal diameters are close in both cases with respective values of $102 \pm 8 \mathrm{~nm}$ and $46 \pm 9 \mathrm{~nm}$.

$\mathrm{X}$-ray diffraction results (ESI Fig. S3 $\dagger$ ) from Ti layer sputtered on FTO electrode exhibit the peaks of $\mathrm{SnO}_{2}$ (FTO) and of the Ti$\alpha$ phase. After synthesis of the nanotubes and annealing at $450{ }^{\circ} \mathrm{C}$, the $\mathrm{TiO}_{2}$ NTs presented an anatase crystalline structure. The intensities of anatase peaks are doubled for electrode $\mathrm{B}$ 

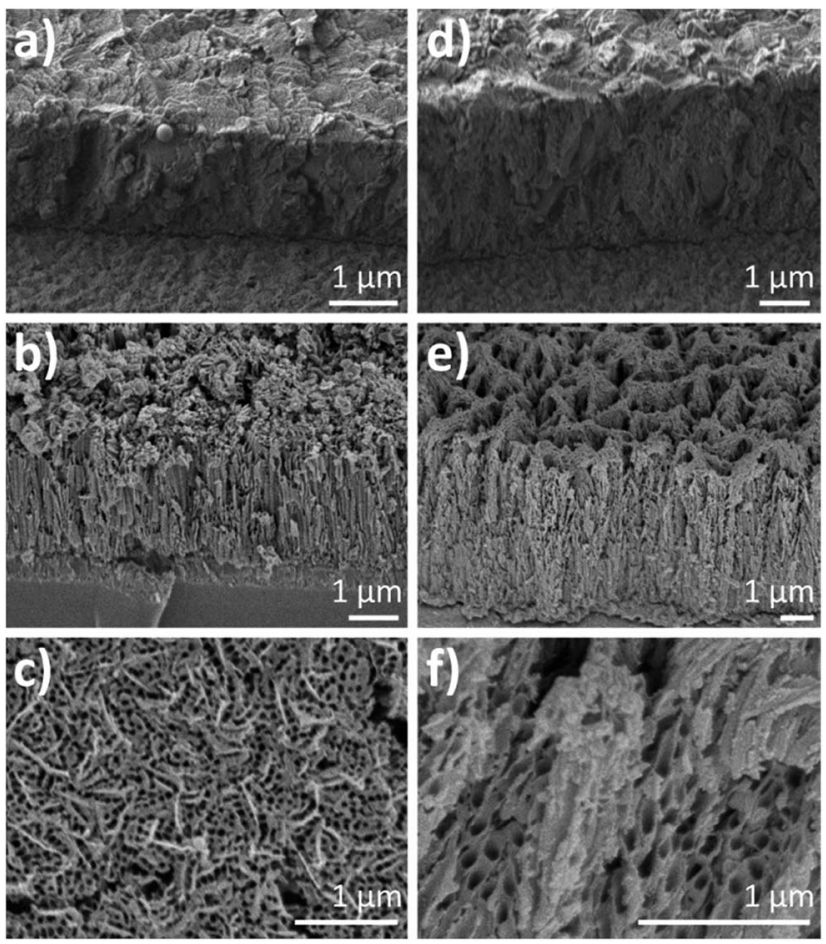

Fig. 2 SEM images of samples tilted at $45^{\circ}$ of PVD deposited Ti layer: (a) $2.4 \mu \mathrm{m}$ - electrode A, (d) $4.4 \mu \mathrm{m}$ - electrode $\mathrm{B}^{\mathrm{TiO}} \mathrm{Ti}_{2} \mathrm{NTs}$ obtained after anodization of (b) electrode $A$ and (e) electrode $B$. Top view SEM images of (c) $\mathrm{TiO}_{2} \mathrm{NTs}$-electrode $\mathrm{A}$ and (f) $\mathrm{TiO}_{2} \mathrm{NTs}$-electrode $\mathrm{B}$.

confirming the higher amount of $\mathrm{TiO}_{2}$ formed. After the formation of the $\mathrm{TiO}_{2}$ NTs, the main peaks of Ti- $\alpha$ at $2 \theta: 40.2^{\circ}$, $52.9^{\circ}$ and $70.7^{\circ}$ were not detected, confirming the almost total consumption of the metallic Ti layer deposited by PVD.

\section{BODIPY dyes characterization}

The three different BODIPY dyes, shown in Fig. 1, have a carboxylic acid function to bind with the $\mathrm{TiO}_{2}$ surface and their different chemical structures produce different colours due to the peripheral styryl arms (Fig. 1). The spectroscopic properties of these dyes and the N719 dye measured by UVvisible absorption and fluorescence emission are presented in Table 1 and Fig. 3a. The BODIPY 1 (B1) has a maximum absorption peak at $500 \mathrm{~nm}$. BODIPY 2 (B2) and 3 (B3) have maximum absorption peaks both at $640 \mathrm{~nm}$ with a shoulder at $600 \mathrm{~nm}$. By comparison, the UV-visible absorption spectra show a stronger absorbance in the visible range for BODIPY dyes than for N719 dye. This is a key property since more than $40 \%$ of the solar spectra energy is in the visible range, between 400-700 $\mathrm{nm}$. The fluorescence emission graph is also shown in Fig. 3a, the N719 dye did not exhibit any light emission resulting from a quenching via energy transfer to the ruthenium centre that is a singlet state.

Another important parameter to take into account for the integration of a dye in the DSCs is the band energy levels. The lowest unoccupied molecular orbital (LUMO) of the dye should be higher $(\approx 0.3 \mathrm{eV})$ than the conduction band edge of the $\mathrm{TiO}_{2}$ to ensure an efficient electron injection and its highest occupied molecular orbital (HOMO) needs to be lower than the chemical energy of the redox couple in the electrolyte for the regeneration of the oxidized dye. ${ }^{1}$ HOMO and LUMO levels of the BODIPY dyes were measured by cyclic voltammetry from the onsets potentials and converted into the vacuum scale following the equations reported in ref. 23 and they were compared with the reported values of the commercial dye N719. ${ }^{57}$ The difference between the HOMO and the LUMO energy levels correspond to the electronic band gap ( $\left.E_{\mathrm{g}}^{\text {elec }}\right)$. The optical band gap $\left(E_{\mathrm{g}}^{\mathrm{opt}}\right)$ was calculated from the absorption-fluorescence onset wavelength $\left(\lambda_{\text {onset }}\right)^{23}$ and values obtained by both methods are in good agreement (Table 1). In Fig. $3 \mathrm{~b}$ are represented the energy levels of these dyes as well as the energy levels of the other components of the DSCs. ${ }^{4,18,58}$ The three BODIPY dyes have energy levels suitable to be integrated in the DSCs with $\mathrm{TiO}_{2}$ : their HOMO are below the redox potential of $\mathrm{I}^{-} / \mathrm{I}_{3}{ }^{-}$and their LUMO are higher than the conduction band minimum (CB) of $\mathrm{TiO}_{2}$. Especially for B1 whose LUMO is $1.2 \mathrm{eV}$ above $\mathrm{TiO}_{2} \mathrm{CB}$. This point is the key to provide enough driving force for the excited electron injection.

Preliminary tests were then conducted by grafting the different BODIPY dyes on $\mathrm{TiO}_{2}$ NTs prepared on titanium foils. The $I-V$ curves and incident photon conversion efficiency (IPCE) results, obtained in back illumination configuration, are presented in ESI (Fig. S4 and Table S2†). The maximal PCE was obtained with the B3 dye, reaching $0.47 \%$. B2 dye has similar energy level position and absorbance properties as B3, but its efficiency is limited to $0.33 \%$. This value quickly decreases with

Table 1 Electrochemical and optical data for the different dyes used

\begin{tabular}{|c|c|c|c|c|c|c|c|c|}
\hline \multirow[b]{2}{*}{ Dye } & \multicolumn{2}{|c|}{ Absorption $^{a}$} & \multicolumn{2}{|l|}{ Emission $^{a}$} & \multirow[b]{2}{*}{$E_{\text {номо }}^{b}(\mathrm{eV})$} & \multirow[b]{2}{*}{$E_{\mathrm{LUMO}}^{b}(\mathrm{eV})$} & \multirow[b]{2}{*}{$E_{\mathrm{g}}^{\text {elec }}(\mathrm{eV})$} & \multirow[b]{2}{*}{$E_{\mathrm{g}}^{\mathrm{opt}}(\mathrm{eV})$ at $\lambda_{\text {onset }}(\mathrm{nm})$} \\
\hline & $\begin{array}{l}\lambda_{\max } \\
(\mathrm{nm})\end{array}$ & $\begin{array}{l}\varepsilon_{\max } \\
\left(\mathrm{M}^{-1} \mathrm{~cm}^{-1}\right)\end{array}$ & $\lambda_{\max }(\mathrm{nm})$ & $\begin{array}{l}\emptyset_{\mathrm{f}} \\
\text { at } \lambda_{\text {exc }}(\mathrm{nm})\end{array}$ & & & & \\
\hline N719 & 516 & 12800 & - & - & $-5.62^{c}$ & $-3.9^{c}$ & 1.72 & - \\
\hline B1 & 500 & 72300 & 511 & $57 \%(540 \mathrm{~nm})$ & -5.36 & -3.03 & 2.33 & $2.46(504 \mathrm{~nm})$ \\
\hline B2 & 645 & 114600 & 660 & $53 \%(700 \mathrm{~nm})$ & -5.05 & -3.31 & 1.74 & $1.91(651 \mathrm{~nm})$ \\
\hline
\end{tabular}

${ }^{a}$ Absorption and emission were measured in solution of the BODIPY dyes in THF and $\mathrm{N} 719$ in EtOH. ${ }^{b} \mathrm{Cyclic}$ voltammetry made in $\mathrm{CH}_{2} \mathrm{Cl}_{2}$ at room temperature. ${ }^{c}$ Energy levels from ref. 56. 

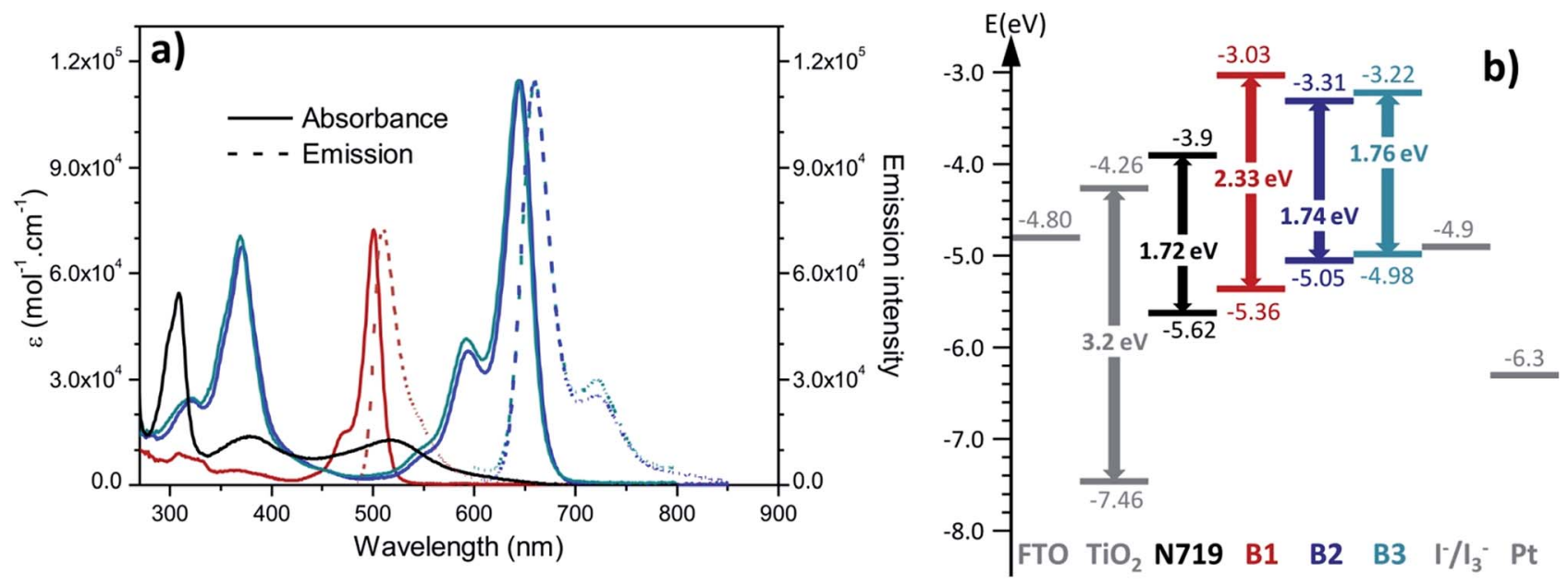

Fig. 3 (a) UV-visible absorption and emission graphs of the dyes in solution, BODIPY dyes dissolved in THF and N719 in EtOH and (b) representation of the energy levels of the dyes from the values determined in Table 1 and all the other components in the DSCs.

time when compared to B3. This can be explained by the better stability of B3 dye due to the replacement of the fluoride groups by ethynyl function groups which avoids the substitution of fluoride by hydroxide. ${ }^{23}$ For B1 dye the efficiency was limited to $0.22 \%$ while a better electron injection was expected for this dye. The origin of this limited efficiency can be its large band gap and the weaker molar extinction of this dye compared to B2 and B3.

Considering these preliminary results, this work was focussed on the optimization and study of the BODIPY 3 dye grafting on $\mathrm{TiO}_{2}$ NTs grown on FTO and the comparison with similar N719 DSCs in front illumination configuration.

\section{Dye adsorption on the $\mathrm{TiO}_{2}$ NT surface}

Solutions of N719 and B3 dyes were prepared with a concentration of $0.5 \mathrm{mM}$ according to the procedure described in experimental part. Fig. 4a-d shows the UV-visible absorption measurements performed on $\mathrm{TiO}_{2}$ NTs electrodes of two different lengths with and without the dye grafted. The characteristic peaks of the dye are visible on all electrodes but slightly red shifted and widened. For N719 we observe a broad peak at $\sim 520 \mathrm{~nm}$ (Fig. 4a and b) and the B3 dye presents 2 peaks; a first one at $\sim 670 \mathrm{~nm}$ and another one less intense at $\sim 580 \mathrm{~nm}$ (Fig. $4 \mathrm{c}$ and d). In order to calculate the quantity of dye grafted on the $\mathrm{TiO}_{2} \mathrm{NTs}$, these electrodes were immersed in an aqueous solution of $\mathrm{KOH}$ to detach the dye from the $\mathrm{TiO}_{2}$ surface and dissolve them in the solution. Then, the quantity of desorbed dye was evaluated by UV-visible absorption. ${ }^{56}$

Fig. 4e shows the quantity of the dye grafted on for each electrode and compared to the theoretical value calculated from the known $\mathrm{TiO}_{2}$ NTs surface area. The theoretical quantity of dye adsorbed per square centimeter of electrode $\left(Q_{\text {dye }}\right)$ was calculated following the eqn (1):

$$
Q_{\text {dye }}\left(\mathrm{mol} \mathrm{cm}^{-2}\right)=\left(\frac{\mathrm{SA}_{\mathrm{NT}}}{S_{\mathrm{dye}} \times N_{\mathrm{A}}}\right) \times \rho_{\mathrm{NT}}
$$

$S_{\text {dye }}$ is the surface occupied by one N719 dye molecule ( 2.43 $\left.\mathrm{nm}^{2}\right) .{ }^{59} \mathrm{SA}_{\mathrm{NT}}$ is the surface area of $1 \mathrm{NT}$, calculated using the length $\left(L_{\mathrm{NT}}\right)$, external radius $\left(R_{\mathrm{NT}}\right)$ and internal radius $\left(r_{\mathrm{NT}}\right)$ of the $\mathrm{TiO}_{2} \mathrm{NTs}$ for both electrodes A and B:

$$
\mathrm{SA}_{\mathrm{NT}}\left(\mathrm{cm}^{2}\right)=\pi R_{\mathrm{NT}}^{2}+2 \pi R_{\mathrm{NT}} L_{\mathrm{NT}}+2 \pi r_{\mathrm{NT}} L_{\mathrm{NT}}
$$

$\rho_{\mathrm{NT}}$ is the density of nanotubes on the electrode (number of NTs per $\mathrm{cm}^{2}$ ) calculated with a correction factor $\varnothing$ taking into account that the NTs are ideally packed in a hexagonal compact system (from top view):

$$
\rho_{\mathrm{NT}}=\frac{1}{\pi R_{\mathrm{NT}}^{2} \times \varnothing}
$$

The quantity of N719 dye grafted on the $\mathrm{TiO}_{2}$ NTs is higher than the theoretical value expected. This might be due to the presence of $\mathrm{TiO}_{2}$ nanoparticles on top of the NTs layer (as it can be seen in Fig. $2 \mathrm{c}$ and $\mathrm{f}$ ) and to the roughness of the nanotube walls. These two features bring supplementary $\mathrm{TiO}_{2}$ surface available for grafting, but not taken into account by the model described by eqn (2) and (3). In the case of B3 dye, 100 times less molecules are grafted on $\mathrm{TiO}_{2}$ NTs surface, than N719 dye and 10 times less than the theoretical values. After dye desorption, the UV-visible graphs of the electrodes were similar to the ones obtained before the grafting: the peaks of the two dyes were not observed anymore (Fig. 4a-d, grey lines), confirming the complete dye removal from the NTs surface. It should be noted that the complete dye desorption from the $\mathrm{TiO}_{2} \mathrm{NTs}$ needed a longer time $(72 \mathrm{~h})$ for B3 dye than for N719 dye $(3 \mathrm{~h})$. This suggests a stronger binding of the $\mathrm{B} 3$ dye with the $\mathrm{TiO}_{2}$ NTs through the carboxylic group. Nevertheless the overall amount of dye molecules is reduced due to a less appropriate molecular structure for a closely packed layer. The difference in grafting strength can be explained by the chemical structure of the two dyes which can lead to different $\mathrm{p} K_{\mathrm{a}}$ of the carboxylic acid groups. The low quantity of B3 dye grafted could also be attributed to its molecular structure: first, the steric bulk of the 

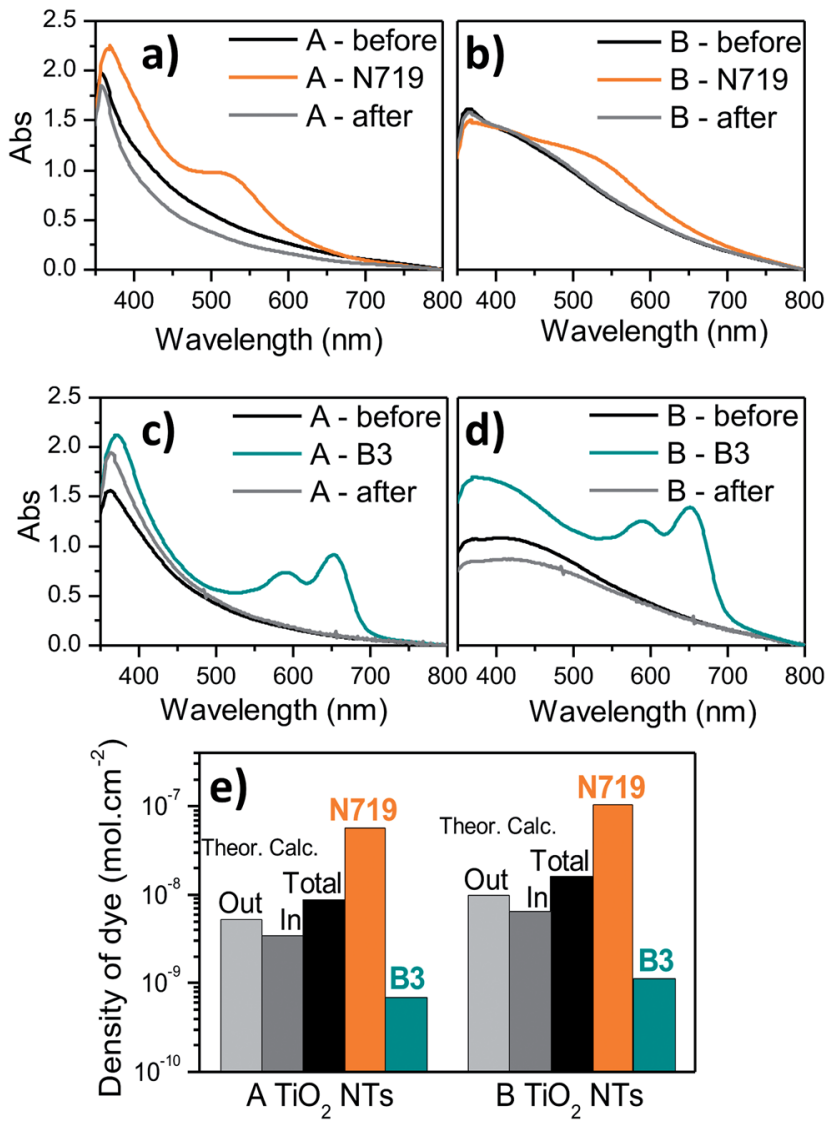

Fig. 4 UV-visible absorption measurements of the $\mathrm{TiO}_{2} \mathrm{NTS}$ on FTO glass electrodes with (color lines) and without (black lines) the dye adsorbed and after dye desorption (grey lines): (a) electrode A-N719, (b) electrode B-N719, (c) electrode A-B3 and (d) electrode B-B3. (e) Quantity of dye adsorbed on each electrode measured by dye desorption and compared with the calculated theoretical value.

peripheral styryl arms (see Fig. 1) can limit a packed layer of B3 dyes molecules. This is evidenced by comparing the grafting of the 3 BODIPY dyes (ESI Table S2 $\dagger$ ): the quantity of B1 dye grafted was higher than B2 and B3 dyes due to the shorter styryl arms, which have less steric hindrance. Second, the oxygen atoms of the styryl arms in B3 dye can interact with the hydroxyl group on the $\mathrm{TiO}_{2}$ NTs surface to form hydrogen bonds, covering the available grafting sites. Furthermore, the N719 dye is more adapted to make a dense layer of molecules on the $\mathrm{TiO}_{2}$ surface due to its more spherical and compact structure with four carboxylic groups compared to the BODIPY dyes that have only one carboxylic group and a more linear structure. Finally other research groups observed an improvement of the grafting density when the organic dyes had bi-anchoring properties rather than only one carboxylic group. ${ }^{60}$

\section{Dye-sensitized solar cells (DSC) performance}

The transparent $\mathrm{TiO}_{2}$ NTs electrodes grafted with the dyes were then tested in DSCs in front illumination configuration. Fig. 5a depicts the current-voltage $I-V$ curves for the best DSCs obtained with electrodes A and B and both dyes out of 6 cells of each condition. Under illumination, the intercept with the voltage axis of the $I-V$ curves, gives the open circuit voltage $\left(V_{\mathrm{oc}}\right)$ which is the maximum voltage the device can reach under light. The intercept of the $I-V$ curves with the $Y$ axis gives the short circuit current $\left(J_{\mathrm{sc}}\right)$, the maximum current the device can produce in given irradiation conditions. The power conversion efficiency (PCE) of the devices can be calculated by eqn (4):

$$
\mathrm{PCE}=\frac{J_{\mathrm{sc}} V_{\mathrm{oc}} \mathrm{FF}}{P_{\text {in }}}
$$

where $P_{\text {in }}$ is the light power density reaching the solar cell and $\mathrm{FF}$, is the fill factor that represents the deviation from the ideal cell behaviour. FF is calculated from eqn (5) using the current $\left(J_{\max }\right)$ and voltage $\left(V_{\max }\right)$ values that gave the maximal power on the $I-V$ curves:

$$
\mathrm{FF}=\frac{J_{\max } V_{\max }}{J_{\mathrm{sc}} V_{\mathrm{oc}}}
$$

The characteristic parameters of the different solar cells efficiency are gathered in Table 2. The N719 dye produced higher current density $\left(J_{\mathrm{sc}}\right)$ in the DSCs. The latter is not surprising comparing the quantity of dye adsorbed on the $\mathrm{TiO}_{2}$ NTs. Furthermore, the B3 DSCs have a smaller open circuit voltage $(\sim 0.4 \mathrm{~V})$, than the N719 based DSCs $(\sim 0.6 \mathrm{~V})$. The value of $V_{\mathrm{oc}}$ is determined by the difference between the Fermi energy level of the $\mathrm{TiO}_{2}$ NTs and the redox potential of the electrolyte.
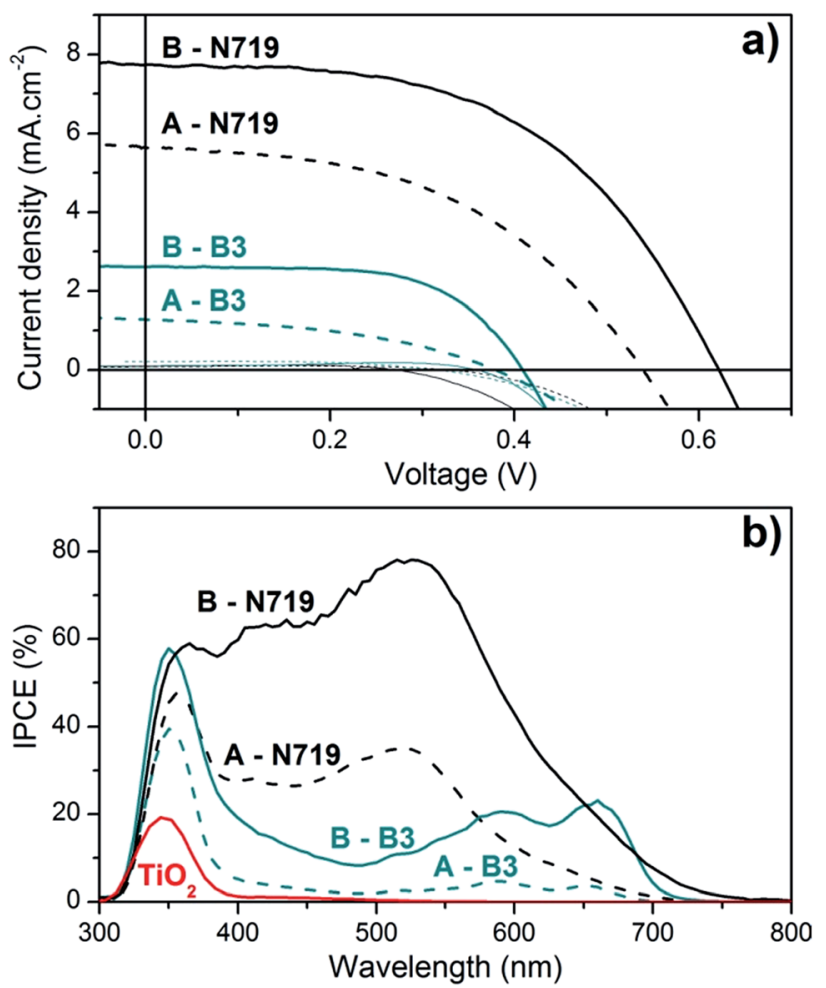

Fig. 5 (a) Current-voltage curves of DSCs with electrode A (dashed lines) and B (solid lines) grafted with N719 (black) and B3 (cyan) dyes and (b) IPCE data of the same cells and a cell of electrode B without dye (red line). 
Table 2 Photovoltaic and IPCE parameters of the DSCs of electrode A and B with N719 and B3 dyes. Quantity of dye adsorbed measured by dye desorption

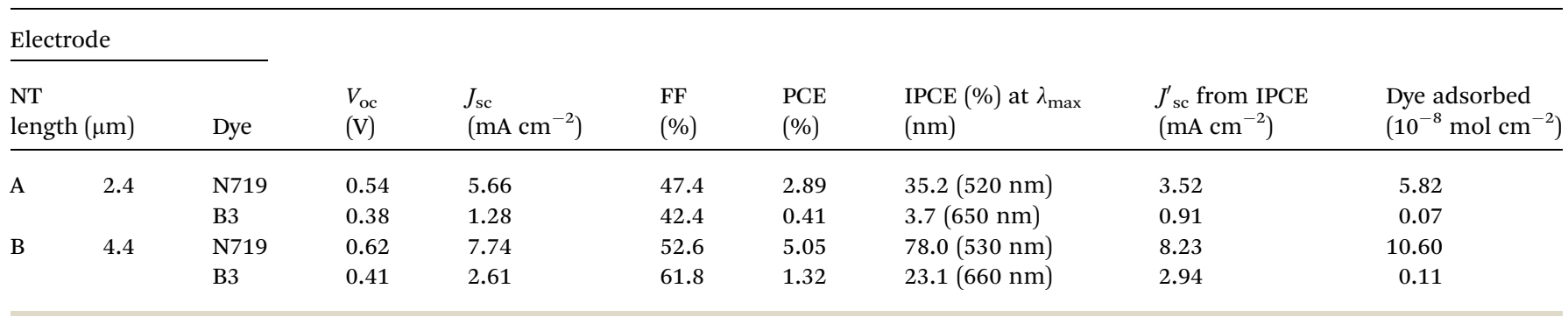

The position of the Fermi level (at $V_{\mathrm{oc}}$ ) will be strongly dependant of the number of electrons populating the conduction band (CB). Indeed, when more electrons are injected into the $\mathrm{TiO}_{2}$ NTs, the Fermi level is closer to the $\mathrm{CB}$, which increases the $V_{\text {oc }}$. Then this $V_{\text {oc }}$ value depends on the energy level of the components of the cell, but also on all the transfer and recombination processes taking place within the DSCs. ${ }^{\mathbf{6 1 , 6 2}}$ The reduced quantity of $\mathrm{B} 3$ dye adsorbed on the $\mathrm{TiO}_{2}$ NTs limits the electron injection and can explain the low $V_{\text {oc }}$ value. It can be observed on the $I-V$ curves: the difference in $V_{\text {oc }}$ between light and dark condition is higher for N719 dye cells than B3 cells. The reduced $J_{\mathrm{sc}}$ and $V_{\mathrm{oc}}$ values for B3 dye based DSCs explained the reduced PCE for these cells.

Nevertheless, even if 100 times less dye molecules are grafted, the PCE values only decreased by a factor 7.0 and 3.8 for A and $\mathrm{B}$ electrode respectively. The overall low performance measured for all cells $(<5 \%)$ can be explained by the limited length of nanotubes available by the synthesis method (limited by the initial Ti thickness). The maximal thickness of $\mathrm{TiO}_{2}-\mathrm{NTs}$ that can be obtained in our case was $4.4 \mu \mathrm{m}$. If we compare this values with the results reported from other research groups for DSCs using the N719 dye and different $\mathrm{TiO}_{2}$ NTs lengths, our PCE values (ESI Fig. S5; $\dagger$ red points) are in good agreement with the overall trend. Higher power conversion efficiencies were obtained with longer $\mathrm{TiO}_{2}$ NTs due to the possibility to absorb more dye on the larger $\mathrm{TiO}_{2}$ NTs surface. Consequently, more photo-generated electrons can be produced from the sun light. ${ }^{12}$ However, the efficiency for our $4.4 \mu \mathrm{m} \mathrm{TiO}{ }_{2} \mathrm{NTs}$ is amongst the highest for this NT length (green points are $\mathrm{TiO}_{2}$ NTs prepared by anodization methods similar to our work).

The Incident Photon Conversion Efficiency (IPCE) of the different DSCs, measured at $0 \mathrm{~V}$ of applied potential, are reported in Fig. $5 \mathrm{~b}$. The IPCE is the ratio between the number of collected electrons and the number of incident photons. It is calculated at each wavelength $(\lambda)$ from the photocurrent $I_{\mathrm{p}}(\lambda)$ and power density $P(\lambda)$ following the eqn (6):

$$
\mathrm{IPCE}=\left(\frac{h c}{e}\right)\left(\frac{I_{\mathrm{p}}(\lambda)}{P(\lambda) \times \lambda}\right)
$$

In agreement with the UV-visible measurements, the IPCE indicates that N719 dye exhibits a broader activity in the visible region compared to the more localized peaks of the B3 dye at 590 and $650 \mathrm{~nm}$. The smaller quantity of B3 dye grafted as well as its limited spectral range of absorption explains the limited PCE of the B3 dye based DSCs. An intense IPCE photoconversion peak appears at $350 \mathrm{~nm}$ for the B3 dye DSCs. To confirm that this peak originates from the dye and not from the $\mathrm{TiO}_{2}$ NTs, that absorb in this region $\left(E_{\mathrm{g}}=3.2 \mathrm{eV}\right)$, we measured IPCE for a similar cell but without any dye (red curve on Fig. $5 b$ ). For that cell, the IPCE at $350 \mathrm{~nm}$ reach $20 \%$ whereas it is $60 \%$ in presence of B3 dye, indicating a strong contribution of the BODIPY dye in the UV part of the spectra.

To compare the results from $I-V$ curves (whole UV-visible spectra) and IPCE (monochromatic wavelengths) experiments, the theoretical photocurrent densities $\left(J^{\prime}\right.$ sc $)$ that would be obtained for the Xe Arc lamp used in $I-V$ measurements were calculated from the IPCE data. For this, the power density of the Xe arc lamp used for $I-V$ curves was measured for each wavelength $\left(P^{\prime}(\lambda)\right)$, then the theoretical photo-current $\left(I_{\mathrm{p}}^{\prime}(\lambda)\right)$ was calculated from IPCE (eqn (7)) and integrated on the whole spectral range (eqn (8)).

$$
\begin{gathered}
I_{\mathrm{p}}^{\prime}(\lambda)=\operatorname{IPCE} \times P^{\prime}(\lambda) \times \lambda \times\left(\frac{e}{h c}\right) \\
J_{\mathrm{sc}}^{\prime}=\int_{\lambda_{\min }}^{\lambda_{\max }} I_{\mathrm{p}}^{\prime}(\lambda) \mathrm{d} \lambda
\end{gathered}
$$

The $J_{\text {sc }}^{\prime}$ values obtained by the IPCE integration are in agreement with the $J_{\text {sc }}$ measured by $I-V$ curves. Both confirm that solar cells with N719 dye have better performance and increasing performance of all the cells for longer $\mathrm{TiO}_{2} \mathrm{NTs}$.

Table 3 shows the number of electrons produced per photon for each peak of the two dyes. In the last column, these values are normalized by the quantity of dye adsorbed and the results give a good indication of the dye charge generation and transfer efficiency. These normalized values clearly indicate that B3 dye has a better capability to absorb light and convert it into electrons that can be injected to the $\mathrm{TiO}_{2}$ NTs than the N719 dye. For instance when comparing the peak at $590 \mathrm{~nm}$ for B3 dye and at 530 for N719 (Table 3, electrode B), the conversion efficiency per dye molecules is 27 times higher for B3 dye.

The stability of the 2 best DSCs obtained with the $4.4 \mu \mathrm{m}$ $\mathrm{TiO}_{2}$ NT length (electrode B) and grafted with N719 dye and B3 dye was analyzed for 50 days. Several measurements of the cells performance were done on this period. The devices were kept in the dark at room temperature between these measurements. In 
Table 3 Number of electrons produced by photon incident light measured by IPCE of each peak of the spectra for N719 dye and B3 dye and the relation of the number of electron with the quantity of dye adsorbed on the electrode

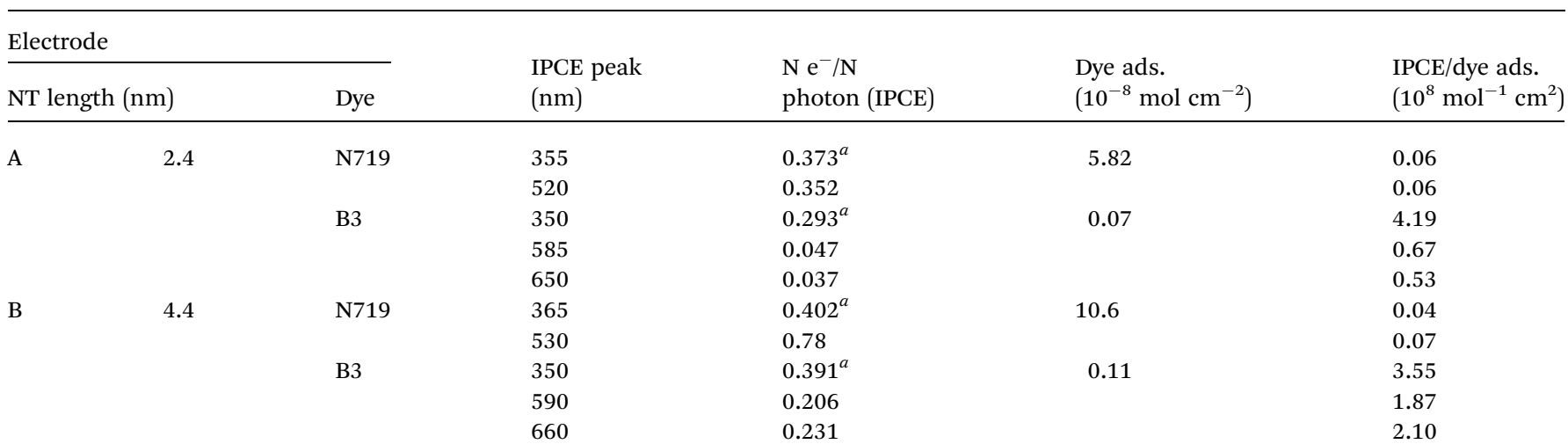

${ }^{a}$ IPCE values for the peaks around $350 \mathrm{~nm}$ were corrected from the contribution of $\mathrm{TiO}_{2}$-NTs, estimated to 0.102 and 0.187 for electrodes A and B respectively.

Fig. S6† we can see the power conversion efficiency of these cells with time showing a good stability for the 2 months tested. These measurements point out that if the sealing of the cells is good, this avoids the electrolyte evaporation and the cells can keep their solar cell performance for a long time.

In the literature, the reported results concerning DSCs based on organic dyes grafted on vertically-aligned $\mathrm{TiO}_{2} \mathrm{NTs}$ were mainly with phtalo-cyanines dyes of CoPc, CuPc and NiPc achieving PCEs of $0.17 \%, 0.12 \%$ and $0.06 \%$ respectively. ${ }^{39}$ The best results were obtained with hemi-squaraine dye (PCE of $0.97 \%$ ) for $18 \mu \mathrm{m}$ long $\mathrm{TiO}_{2} \mathrm{NT}$ and using an iodine-free electrolyte this value was increased to $2.03 \%{ }^{40}$ Even with not optimized NTs length and low quantity of dye grafted, the PCE values obtained with the B3 dye (1.32\%) are promising for this class of organic BODIPY dye. Indeed, the few studies reporting BODIPY dyes in DSCs reported efficiency ranging between 0.1 and $2.5 \% .{ }^{29}$ Only one publication reported efficiency above $5 \%$, but for BODIPY dye with a different chemical structure. ${ }^{30}$ All these studies were conducted on DSCs using $\mathrm{TiO}_{2}$ NPs.

\section{Electrochemical Impedance Spectroscopy (EIS)}

The charge transport and recombination processes within the DSCs were further investigated by Electrochemical Impedance Spectroscopy (EIS). Fig. 6 shows the EIS Nyquist plots of the best cells measured with both nanotube lengths and both type of dyes. These measurements were collected in the dark and under irradiation $\left(50 \mathrm{~mW} \mathrm{~cm}^{-2}\right)$ at $0.6 \mathrm{~V}$ for the $\mathrm{N} 719$ dye based DSCs (Fig. 6a) and $0.4 \mathrm{~V}$ for the B3 dye based DSCs (Fig. 6b), according to the measured $V_{\mathrm{oc}}$ values (Table 2). The experimental EIS data were fitted with the EC-Lab® Zfit software to calculate the values of each $R$ and $Q$ elements of the equivalent circuit reported in Fig. $6 \mathrm{c}$. The calculated parameters for all the cells are gathered in Table S3. $\dagger$

The Nyquist plots in Fig. 6 present two semicircles. The small semicircle at high frequencies is attributed to the redox reaction at the platinum counter electrode $\left(Q_{2} \& R_{2}\right)$ and the large semicircle at lower frequencies is linked to the charge transfer
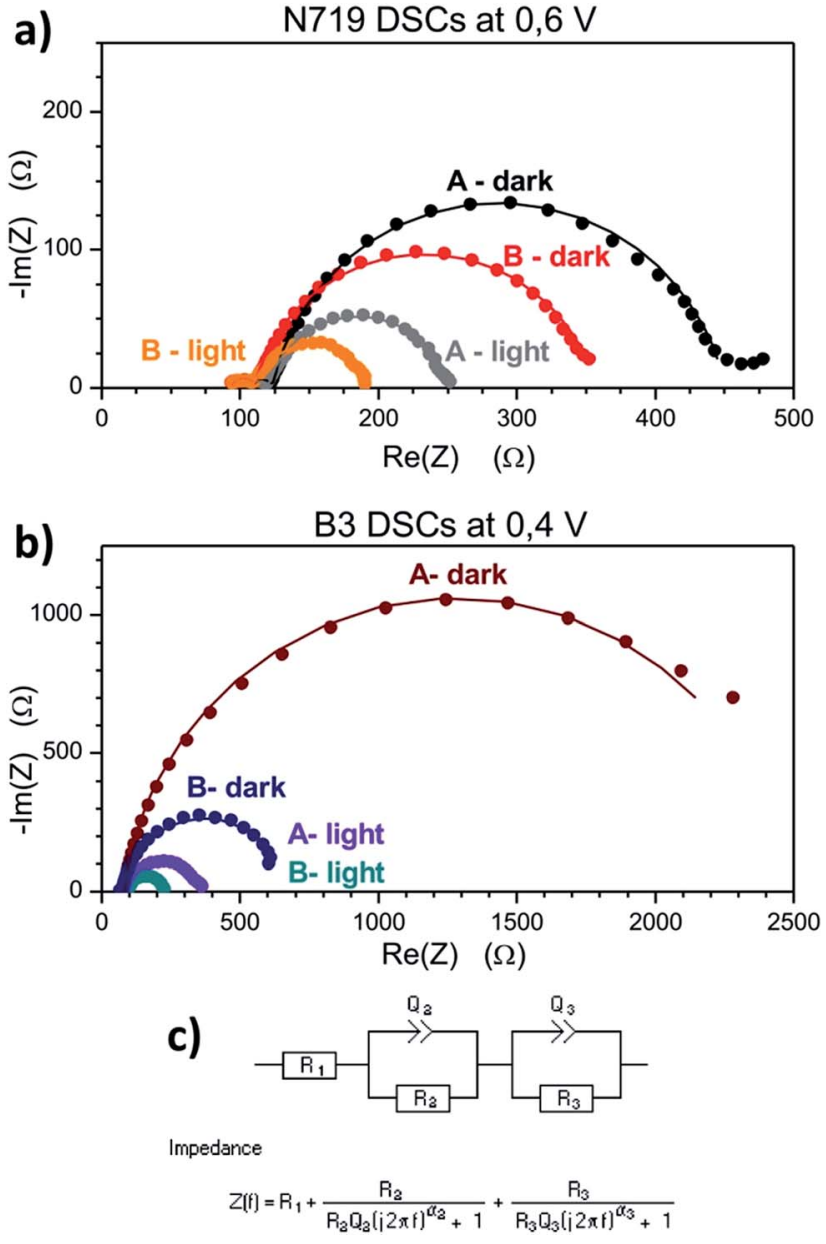

Fig. 6 Nyquist plots of the EIS measurements in the dark and under light for both electrodes A and B at (a) $0.6 \mathrm{~V}$ for the dye N719 based DSCs and (b) at $0.4 \mathrm{~V}$ for the dye B3 based DSCs. Data obtained (dots) and the fitted results (line). (c) The equivalent circuit used to fit the EIS results. 
at the interface between electrode $\left(\mathrm{TiO}_{2} \mathrm{NTs}+\right.$ dye $)$ and electrolyte $\left(Q_{3} \& R_{3}\right)$. The higher is the $R_{3}$ value, the less electron losses will occur due to back recombination, taking place from the excited electron in the dye back to the redox species in the electrolyte. It can be clearly seen by comparing the EIS graphs in dark and under light irradiation in Fig. 6. Under irradiation the charge carrier density in the $\mathrm{CB}$ of $\mathrm{TiO}_{2}$ increases and consequently the back recombination processes, then values of $R_{3}$ decrease for all cells (Table $\mathrm{S} 3 \dagger$ ). The resistance $R_{3}$ also decreases for longer $\mathrm{TiO}_{2}$ NTs for both dyes, this is due to the larger surface area: since more dye is grafted, more electrons are photogenerated, maintaining the high steady-state electron density in the $\mathrm{TiO}_{2}$ NTs CB. ${ }^{\mathbf{6 3 , 6 4}}$ Generally, higher $R_{3}$ values are obtained for the B3 DSCs, however, the decrease in $R_{3}$ is more pronounced for the B3 dye solar cells under light irradiation, especially with electrode A. The more pronounced change in $R_{3}$ for the BODIPY dye under irradiation is probably due to the low quantity of molecules grafted on the $\mathrm{TiO}_{2}$ NTs: the electron transfer in $\mathrm{TiO}_{2}$ depends of trapping/detrapping phenomenon and a lower concentration of photo-generated electrons implies an increase of the electron transfer time constant and consequently an increase of the recombination. This lower concentration of photo-generated charge carriers when using the B3 dye, observed by the higher $R_{3}$ value, can also explain the reduced $V_{\mathrm{oc}}$ values of these cells.

The electron transfer time constant lifetime $\left(\tau_{n}\right)$ can be determined from EIS data following eqn (9):

$$
\tau_{\mathrm{n}}=\frac{1}{2 \pi f_{\mathrm{mid}}}
$$

where $f_{\text {mid }}$ is the frequency peak observed on Bode plot (Fig. S7 $\dagger$ ), in the 1-100 $\mathrm{Hz}$ range. The highest electron lifetime was $96 \mathrm{~ms}$ for the short $\mathrm{TiO}_{2}$ NTs (electrode A) with B3 dye in dark conditions (Table $\mathrm{S} 3 \dagger$ ). This value was reduced to $45 \mathrm{~ms}$ for the $\mathrm{TiO}_{2}$ NTs of electrode B with the same dye. In all condition, the electron transfer time constants are lower for N719 dye as expected since more electron are injected in the conduction band. Under light irradiation, the electron lifetimes decrease for all the cells confirming the better charge transport.

\section{Density function theory calculations}

Density Functional Theory (DFT) calculations were performed to determine structure/properties relation of the BODIPY dyes in order to compare with the experimental results and also to determine the limiting point and how to overcome them. Theoretical approaches based on DFT have been developed and applied successfully to understand the elementary steps involved in the working principle of DSCs. ${ }^{65,66}$ Several information can be extracted from the structure of the dye and DFT calculations based on the isolated molecule. ${ }^{54}$

The structures of the three BODIPY dyes were optimized by DFT. It appears that the benzoic acid group is perpendicular to the BODIPY part of the molecule. The consequence is an electronic decoupling between the anchoring group and the rest of the molecule. From a spectroscopic point of view, the three first
Table 4 Experimental and computed absorption properties of B1, B2 and $\mathrm{B} 3$ dyes. $f_{\mathrm{DFT}}$ is the computed oscillator strength

\begin{tabular}{lllll}
\hline Dye & $\lambda_{\exp }(\mathrm{nm})$ & $\begin{array}{l}\varepsilon_{\exp } \\
\left(\mathrm{mol}^{-1} \mathrm{~cm}^{-1}\right)\end{array}$ & $\begin{array}{l}\lambda_{\text {DFT }} \\
(\mathrm{nm})\end{array}$ & $\begin{array}{l}f_{\text {DFT }} \\
(\text { a.u. })\end{array}$ \\
\hline B1 & 500 & 73200 & 441 & 0.60 \\
B2 & 645 & 114600 & 591 & 1.15 \\
& 618 & 36464 & & \\
& 367 & 64076 & 365 & 1.43 \\
B3 & 315 & 22042 & 330 & 0.70 \\
& 645 & 105200 & 591 & 1.08 \\
& 586 & 34634 & & \\
& 366 & 60654 & 366 & 1.14 \\
& 317 & 19365 & 331 & 0.74 \\
\hline
\end{tabular}

transitions of these dyes were computed at the TD-DFT level (Table 4).

From the experimental spectra, it seems that the first and most intense transition $(\approx 630 \mathrm{~nm})$ is marked by a strong vibronic coupling, splitting the transition into two well-resolved peaks for B2 and B3. This vibronic nature is established both from the experimental fluorescence spectrum and from previous TD-DFT work performed on similar molecules. For this transition, TD-DFT reproduces the bathochromic and hyperchromic shift observed from B1 to B2 and B3. The discrepancy between theory and experiment for this transition is relatively large for TD-DFT calculation, but clearly expected for this type of molecule. ${ }^{\mathbf{4 9 , 5 1}}$

The electron density variations between the ground and excited state for this transition around $600 \mathrm{~nm}$ are presented in Fig. 7 along with the charge transfer length, $d_{\mathrm{CT}}$, extracted from these electronic density variations. This $d_{\mathrm{CT}}$ indice is the distance between the barycentres of the electron density increasing and decreasing regions (red and green areas on Fig. 7 and 8). From this figure, it appears that the transition has a local $\pi-\pi^{*}$ character more than a charge transfer character. On the absorption spectra of B2 and B3, two other transitions are observed around 366 and $315 \mathrm{~nm}$ (Fig. 3a). TD-DFT calculations suggest that these transitions are not two vibronic bands of the same transition but two electronic transitions. The Fig. 8 presents the variation of electron density of these two transitions for the B3 dye (similar results are obtained on B2 dye). It appears that the transition at $366 \mathrm{~nm}$ has a larger charge transfer character than the first transition of the molecule. We can also notice that the anchoring benzoic group doesn't contribute to any of the transitions involved in the absorption spectra, in agreement with the geometry analysis.

These spectroscopic considerations help to understand the photovoltaic results obtained with the B3 dye. If we assume that the IPCE spectrum presented on Fig. $5 \mathrm{~b}$ is mainly governed by the injection efficiency from the excited dye to the $\mathrm{TiO}_{2}$ (i.e. IPCE $\approx \Phi_{\text {inj }}$, expecting that LHE $\approx 100 \%$ and $\eta_{\text {coll }} \approx 100 \%$ ) at the wavelength of the maximum dye absorptions, we can assume that the injection efficiency for the B3 dye at $660 \mathrm{~nm}$ is around $20 \%$ for electrode B. For the same cell, the injection of the B3 dye at $350 \mathrm{~nm}$ is around $40 \%$ (60\% of IPCE subtracted by 


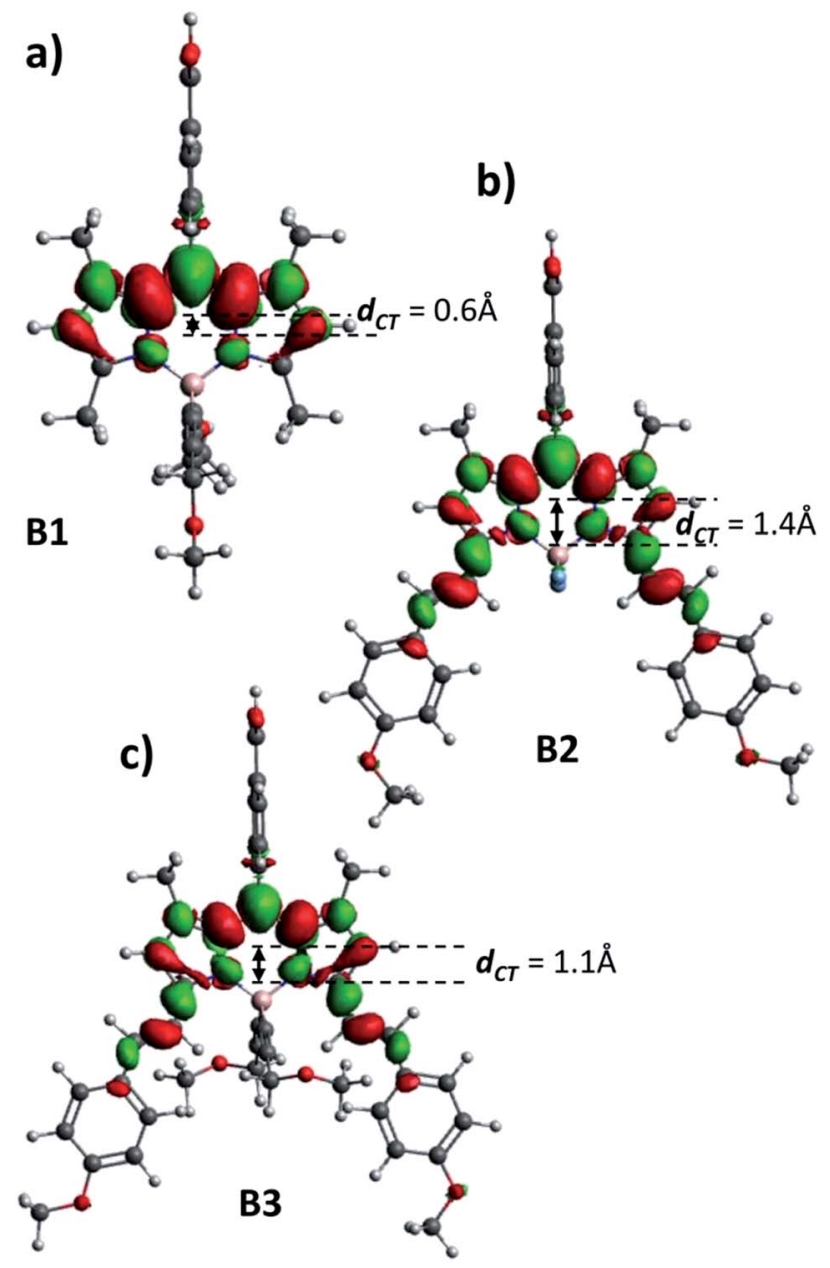

Fig. 7 Computed variation of the electron density for the BODIPY dyes associated to the first electronic transition along with the charge transfer length (a), (b) and (c) being B1, B2 and B3 dyes respectively (iso value 0.0004 a.u.). Green and red areas present the increase and decrease of the electron density respectively. Atoms $\mathrm{C}, \mathrm{H}, \mathrm{N}, \mathrm{O}$ and $\mathrm{B}$ are in grey, white, blue, red and pink respectively.

$20 \%$ of injection from $\mathrm{TiO}_{2}$, Fig. S8 $\dagger$ ). Therefore, the injection efficiency of $\mathrm{B} 3$ at $350 \mathrm{~nm}$ is the twice of the injection efficiency at $600 \mathrm{~nm}$.

The difference between the injection efficiencies from these peaks at $660 \mathrm{~nm}$ and $350 \mathrm{~nm}$ can be understood from the charge transfer nature of the transitions involved. Since a large charge transfer transition is beneficial for a better charge separation, the transition at $350 \mathrm{~nm}$ (computed to be $S_{0} \rightarrow S_{2}$ ) should be more efficient for photocurrent generation than the one at 660 $\mathrm{nm}$ (computed to be $\mathrm{S}_{0} \rightarrow \mathrm{S}_{1}$ ), corresponding to what is observed experimentally. The limited injection efficiency of this family of dye can be explained by the reduced amount of dye grafted, but also by the weak contribution of the benzoic acid group to the excited state. A larger injection can be obtained by increasing the electronic coupling between the benzoic group and the BODIPY core that is low because of the large dihedral angle between the two chemical groups. In other words, the efficiency of this family of dyes could be improved by increasing

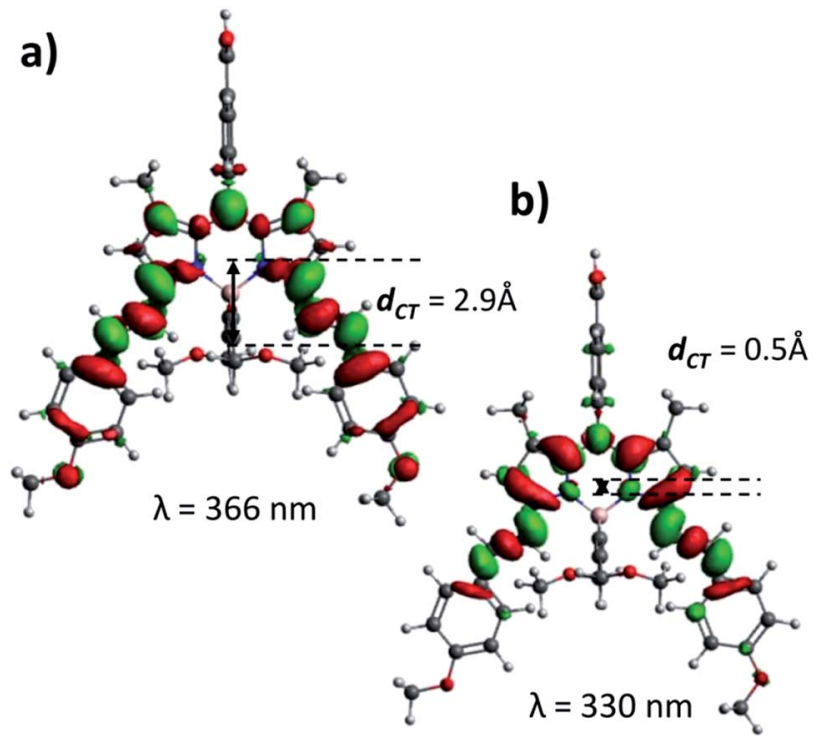

Fig. 8 Computed variation of the electron density for the BODIPY B3 dye along with the charge transfer length for the two transitions observed in the UV part of the spectrum (isovalue 0.0004 a.u.). Atoms $\mathrm{C}, \mathrm{H}, \mathrm{N}, \mathrm{O}$ and $\mathrm{B}$ are in grey, white, blue, red and pink respectively.

the planarity of the molecule, for instance by removing the two methyl groups located on the BODIPY core.

\section{Conclusions}

A dye-sensitized solar cell combining BODIPY dye and verticallyaligned $\mathrm{TiO}_{2}$ NTs was successfully made for the first time. The DSCs performance is measured and compared with N719 dye based DSCs. Power conversion efficiency of $1.32 \%$ were obtained with the B3 dye, for $\mathrm{TiO}_{2}$ NTs of $4.4 \mu \mathrm{m}$ length. This PCE is quite high when compared to other organic dyes, grafted on $\mathrm{TiO}_{2}$ NTs, reported in the literature $(<1 \%)$. Nevertheless, the efficiency is lower than our measurement done with the N719 sensitizer in a similar DSC configuration (5.05\%). However, considering the low quantity of $\mathrm{B} 3$ adsorbed on the $\mathrm{TiO}_{2}$ NTs surface, this PCE is much higher than expected. Indeed, the quantity of N719 dye adsorbed was 100 times higher than the quantity of B3 dye but the PCE of the N719 dye DSCs is only 4 times higher than the B3 dye cells. This can be explained by the strong absorption coefficient of the B3 dye and the good photon to electron conversion and injection efficiency of the BODIPY dye evidenced when IPCE is normalized by the quantity of dye grafted for each solar cell. In this case, the BODIPY dye presents more than 10 times better photo-conversion efficiency. EIS measurements also emphasize the good properties of this BODIPY dye by indicating a reduced back transfer recombination than for N719 dye. But since less BODIPY dye molecules are grafted, the low quantity of injected electron can explain the low $V_{\text {oc }}$ value of the B3 DSCs as confirmed by EIS results.

DFT calculations made on the BODIPY dye are in agreement with the experimental results. They help us to understand the limit of the charge transfer in these molecules and to propose modification in the chemical structure of the BODIPY dyes that 
might be beneficial to increase the solar cell performance. In particular the benzoic acid group involved in the grafting is perpendicular to the BODIPY part of the molecule resulting in an electronic decoupling and limited charge transfer toward the $\mathrm{TiO}_{2}$.

Considering these results, several aspects have to be improved like increasing the NTs length for a better light absorption and mainly increasing the amount of B3 dye grafted. One way to increase the dye adsorption could be adding extra carboxylic groups to the B3 dye, similar to the N719 dye, to see if it improves the linkage with the $\mathrm{TiO}_{2}$ surface. Additionally, the carboxylic group could be modified to obtain more planar molecules to improve the electron injection to the $\mathrm{TiO}_{2}$. The synthesis of improved BODIPY dyes, according to these preliminary results, is currently underway.

\section{Acknowledgements}

This work was supported by the IdEX - W13RTVK project from the University of Strasbourg. The authors want to acknowledge Raymond Ziessel and Gilles Ulrich for their discussion and help concerning the BODIPY properties and grafting, Thierry Romero for recording SEM images, Sergey N. Pronkin for his help analyzing the EIS data, Manuel Acosta for the titanium sputtering and Elsa Ceci for her help in organic synthesis. The authors are grateful to the "Pole Scientifique de Modélisation Numérique” (PSMN) for providing computational resources.

\section{References}

1 A. Hagfeldt, G. Boschloo, L. Sun, L. Kloo and H. Pettersson, Chem. Rev., 2010, 110, 6595-6663.

2 K. Kakiage, Y. Aoyama, T. Yano, K. Oya, J. Fujisawa and M. Hanaya, Chem. Commun., 2015, 51, 15894-15897.

3 B. O'Regan, Nature, 1991, 353, 737-740.

4 M. Grätzel, Nature, 2001, 414, 338-344.

5 R. Sánchez-Tovar, R. M. Fernández-Domene, D. M. GarcíaGarcía and J. García-Antón, J. Power Sources, 2015, 286, 224-231.

6 M. Ongaro, A. Mardegan, A. M. Stortini, M. Signoretto and P. Ugo, Nanotechnology, 2015, 26, 165402.

7 D. Spitzer, T. Cottineau, N. Piazzon, S. Josset, F. Schnell, S. N. Pronkin, E. R. Savinova and V. Keller, Angew. Chem., Int. Ed. Engl., 2012, 51, 5334-5338.

8 A. Fujishima and K. Honda, Nature, 1972, 238, 37-38.

9 G. Carré, L. Garnier, J. Moeller-Siegert, J.-P. Gies, V. Keller, P. André and N. Keller, RSC Adv., 2015, 5, 38859-38867.

10 G. K. Mor, O. K. Varghese, M. Paulose, K. Shankar and C. A. Grimes, Sol. Energy Mater. Sol. Cells, 2006, 90, 20112075.

11 P. Roy, S. Berger and P. Schmuki, Angew. Chem., Int. Ed. Engl., 2011, 50, 2904-2939.

12 M. Paulose, K. Shankar, O. K. Varghese, G. K. Mor and C. A. Grimes, J. Phys. D: Appl. Phys., 2006, 39, 2498-2503.

13 M. Adachi, Y. Murata, I. Okada and S. Yoshikawa, J. Electrochem. Soc., 2003, 150, G488-G493.
14 J. Zhang, S. Li, H. Ding, Q. Li, B. Wang, X. Wang and H. Wang, J. Power Sources, 2014, 247, 807-812.

15 Y. Ooyama and Y. Harima, Eur. J. Org. Chem., 2009, 29032934.

16 R. M. El-Shishtawy, Int. J. Photoenergy, 2009, 1-21.

17 A. Yella, H.-W. Lee, H. N. Tsao, C. Yi, A. K. Chandiran, M. K. Nazeeruddin, E. W.-G. Diau, C.-Y. Yeh, S. M. Zakeeruddin and M. Grätzel, Science, 2011, 334, 629-634.

18 B. E. Hardin, E. T. Hoke, P. B. Armstrong, J.-H. Yum, P. Comte, T. Torres, J. M. J. Fréchet, M. K. Nazeeruddin, M. Grätzel and M. D. McGehee, Nat. Photonics, 2009, 3, 406-411.

19 T. Horiuchi, H. Miura, K. Sumioka and S. Uchida, J. Am. Chem. Soc., 2004, 126, 12218-12219.

20 K. Hara, T. Sato, R. Katoh, A. Furube, Y. Ohga, A. Shinpo, S. Suga, K. Sayama, H. Sugihara and H. Arakawa, J. Phys. Chem. B, 2003, 107, 597-606.

21 R. Katoh, A. Furube, S. Mori, M. Miyashita, K. Sunahara, N. Koumura and K. Hara, Energy Environ. Sci., 2009, 2, 542-546.

22 D. P. Hagberg, T. Edvinsson, T. Marinado, G. Boschloo, A. Hagfeldt and L. Sun, Chem. Commun., 2006, 2245-2247.

23 D. Kumaresan, R. P. Thummel, T. Bura, G. Ulrich and R. Ziessel, Chem.-Eur. J., 2009, 15, 6335-6339.

24 T. Rousseau, A. Cravino, T. Bura, G. Ulrich, R. Ziessel and J. Roncali, Chem. Commun., 2009, 1673-1675.

25 D. Frath, J. E. Yarnell, G. Ulrich, F. N. Castellano and R. Ziessel, ChemPhysChem, 2013, 3348-3354.

26 M. Benstead, G. H. Mehl and R. W. Boyle, Tetrahedron, 2011, 67, 3573-3601.

27 S. Hattori, K. Ohkubo, Y. Urano, H. Sunahara, T. Nagano, Y. Wada, N. V Tkachenko, H. Lemmetyinen and S. Fukuzumi, J. Phys. Chem. B, 2005, 109, 15368-15375.

28 S. Erten-Ela, M. D. Yilmaz, B. Icli, Y. Dede, S. Icli and E. U. Akkaya, Org. Lett., 2008, 10, 3299-3302.

29 S. P. Singh and T. Gayathri, Eur. J. Org. Chem., 2014, 22, 4689-4707.

30 Y. Kubo, D. Eguchi, A. Matsumoto, R. Nishiyabu, H. Yakushiji, K. Shigaki and M. Kaneko, J. Mater. Chem. A, 2014, 2, 5204-5211.

31 Z. E. Galateia, N. Agapi, N. Vasilis, G. D. Sharma and C. G. Athanassios, J. Mater. Chem. C, 2015, 3, 5652-5664.

32 M. Mao, X.-L. Zhang, X.-Q. Fang, G.-H. Wu, Y. Ding, X.-L. Liu, S.-Y. Dai and Q.-H. Song, Org. Electron., 2014, 15, 2079-2090. 33 J. Zhang, F. Lu, S. Qi, Y. Zhao, K. Wang, B. Zhang and Y. Feng, Dyes Pigm., 2016, 128, 296-303.

34 G. Ulrich, R. Ziessel and A. Harriman, Angew. Chem., Int. Ed., 2008, 47, 1184-1201.

35 M. Kollmannsberger, T. Gareis, S. Heinl, J. Daub and D. J. Breu, Angew. Chem., Int. Ed., 1997, 36, 1333-1335.

36 J. M. J. Brom and J. L. Langer, J. Alloys Compd., 2002, 338, 112-115.

37 K. Rurack, M. Kollmannsberger and J. Daub, New J. Chem., 2001, 25, 289-292.

38 D. R. Monsma Jr, F. J. Barton, A. C. Kang, H. C. Brassard, D. L. Haughland and R. P. Sibley, J. Neurochem., 1989, 52, 1641-1644. 
39 N. F. Atta, H. M. A. Amin, M. W. Khalil and A. Galal, Int. J. Electrochem. Sci., 2011, 6, 3316-3332.

40 D. Pugliese, A. Lamberti, F. Bella, A. Sacco, S. Bianco and E. Tresso, Org. Electron., 2014, 15, 3715-3722.

41 L. Tsui, J. Huang, M. Sabat and G. Zangari, ACS Sustainable Chem. Eng., 2014, 2, 2097-2101.

42 T. Cottineau, N. Béalu, P.-A. Gross, S. N. Pronkin, N. Keller, E. R. Savinova and V. Keller, J. Mater. Chem. A, 2013, 1, 21512160.

43 T. Cottineau, S. N. Pronkin, M. Acosta, C. Mény, D. Spitzer and V. Keller, Sens. Actuators, B, 2013, 182, 489-497.

44 T. Rousseau, A. Cravino, T. Bura, G. Ulrich, R. Ziessel and J. Roncali, J. Mater. Chem., 2009, 19, 2298-2300.

45 M. J. Frisch, G. W. Trucks, H. B. Schlegel, G. E. Scuseria, M. A. Robb, J. R. Cheeseman, S. G. V. Barone, B. Mennucci, G. A. Petersson, H. Nakatsuji, C. M. X. Li, H. P. Hratchian, A. F. Izmaylov, J. Bloino, G. Zheng, J. L. Sonnenberg, M. Hada, M. Ehara, K. Toyota, R. Fukuda, J. Hasegawa, M. Ishida, T. Nakajima, Y. Honda, O. Kitao, H. Nakai, T. Vreven, J. J. A. Montgomery, J. E. Peralta, F. Ogliaro, M. Bearpark, J. J. Heyd, E. Brothers, K. N. Kudin, N. V. Staroverov, R. Kobayashi, J. Normand, K. Raghavachari, A. Rendell, J. C. Burant, S. S. Iyengar, J. Tomasi, M. Cossi, N. Rega, N. J. Millam, M. Klene, J. E. Knox, J. B. Cross, V. Bakken, C. Adamo, J. Jaramillo, R. Gomperts, R. E. Stratmann, O. Yazyev, A. J. Austin, R. Cammi, C. Pomelli, J. W. Ochterski, R. L. Martin, K. Morokuma, G. V. Zakrzewski, G. A. Voth, P. Salvador, J. J. Dannenberg, S. Dapprich, D. A. D. Ö. Farkas, J. B. Foresman, J. V. Ortiz, J. Cioslowski and D. J. Fox, Gaussian Inc, 2009.

46 W. J. Hehre, R. Ditchfield and J. A. Pople, J. Chem. Phys., 1972, 56, 2257-2261.

47 M. M. Francl, W. J. Pietro, W. J. Hehre, J. S. Binkley and M. S. Gordon, J. Chem. Phys., 1982, 77, 3654.

48 C. Adamo and V. Barone, J. Chem. Phys., 1999, 110, 61586170.
49 Y. Zhao and D. G. Truhlar, Theor. Chem. Acc., 2008, 120, 215241.

50 M. R. Momeni and A. Brown, J. Chem. Theory Comput., 2015, 11, 2619-2632.

51 S. Chibani, B. Le Guennic, A. Charaf-Eddin, A. D. Laurent and D. Jacquemin, Chem. Sci., 2013, 4, 1950-1963.

52 J. Tomasi, B. Mennucci and R. Cammi, Chem. Rev., 2005, 105, 2999-3093.

53 V. Barone and M. Cossi, J. Phys. Chem. A, 1998, 102, 19952001.

54 T. Le Bahers, C. Adamo and I. Ciofini, J. Chem. Theory Comput., 2011, 7, 2498-2506.

55 C. Adamo, T. Le Bahers, M. Savarese, L. Wilbraham, G. García, R. Fukuda, M. Ehara, N. Rega and I. Ciofini, Coord. Chem. Rev., 2015, 304-305, 166-178.

56 N. R. Neale, N. Kopidakis, J. Van De Lagemaat, M. Grätzel and A. J. Frank, J. Phys. Chem. B, 2005, 109, 23183-23189.

57 T. Daeneke, T.-H. Kwon, A. B. Holmes, N. W. Duffy, U. Bach and L. Spiccia, Nat. Chem., 2011, 3, 211-215.

58 J. Chung, J. Lee and S. Lim, Phys. B, 2010, 405, 2593-2598.

59 C. Lin, F.-Y. Tsai, M.-H. Lee, C.-H. Lee, T.-C. Tien, L.-P. Wang and S.-Y. Tsai, J. Mater. Chem., 2009, 19, 2999-3003.

60 S. Manoharan, A. M. Asiri and S. Anandan, Sol. Energy, 2016, 126, 22-31.

61 S. R. Raga, E. M. Barea and F. Fabregat-Santiago, J. Phys. Chem. Lett., 2012, 3, 1629-1634.

62 W.-Q. Wu, H.-S. Rao, Y.-F. Xu, Y.-F. Wang, C.-Y. Su and D.-B. Kuang, Sci. Rep., 2013, 3, 1892-1897.

63 B.-E. Ahn, H. S. Kim, S. K. Yang, K.-S. Ahn and S. H. Kang, J. Photochem. Photobiol., A, 2014, 274, 20-26.

64 J. Choi, Y. S. Kwon and T. Park, J. Mater. Chem. A, 2014, 2, 14380-14385.

65 T. Le Bahers, E. Brémond, I. Ciofini and C. Adamo, Phys. Chem. Chem. Phys., 2014, 16, 14435-14444.

66 T. Le Bahers, T. Pauporté, P. P. Lainé, F. Labat, C. Adamo and I. Ciofini, J. Phys. Chem. Lett., 2013, 4, 1044-1050. 